\title{
A retrospective comparative study of intramedually nailing versus plating in the management of diaphyseal both-bone forearm fractures among adults
}

\author{
Reddy R.C. ${ }^{1}$, M. Anil Kumar ${ }^{2}$ \\ ${ }^{1}$ Dr. R. Chandrasekhar Reddy, Assistant Professor, Department on of Orthopaedics, Fathima Institute of Medical \\ Sciences, Kadapa, Andhra Pradesh, ${ }^{2}$ Dr. M. Anil Kumar, Assistant Professor, Department of Orthopaedics, Rajiv Gandhi \\ Institute of Medical Sciences, Kadapa, Andhra Pradesh, India.
}

Corresponding Author: Dr. M. Anil Kumar, No.42/344_13_1, Bhagyanagar Colony, Kadapa, Andhra Pradesh, India. E-mail: dr.anil.malaka@gmail.com

\begin{abstract}
Introduction: Aim was to compare the time taken for clinical and radiological union between intramedually nailing versus plating in the management of diaphyseal both-bone forearm fractures among adults. Materials and Methods: This retrospective study compared two different procedures used as a part of routine care in treatment of both bones fractures of forearm. The functional outcomes were radiological union and range of motion. The fractures were stratified according to AO/SIF classification. The patients were assessed using the Grace-Eversmann criteria. Results: A total of 65 participants were included in the study with 36 participants in plating and 29 in IMN group. The mean age in plating group was $43.2 \pm 4.8$ years and $44.78 \pm 5.34$ years in IMN group. There was no significant difference in the basic demographic characteristics between the groups. The mean time taken for radiological union in plating group andIMN group was $11.23 \pm 2.16$ weeks and $13.87 \pm 3.32$ weeks. There was a statistically significant differencebetween the groups with regard to mean operating time, radiological union and mean supination ( $\mathrm{P}$ Value $<0.05)$. In plating group, $27(75 \%)$ participants had excellent, $6(16.66 \%)$ participants had good and $3(8.33 \%)$ participants had acceptable functional outcome. In IMN group, 23 (82.75\%) participants had excellent, 4 (13.79\%) participants had good, 1 (3.44\%) participant had acceptable functional outcome and 1 (3.44\%) participant had unacceptable functional outcome. Conclusion: Radiological union was lesser and the range of motion was more for plating group. However, both modalities of treatment provided equally satisfactory results.
\end{abstract}

Keywords: Forearm, Fracture, Diaphyses, Internal fixation, Dynamic compression plate, intramedullary nail

\section{Introduction}

The fractures of forearm bones are increasing in frequency due to active lifestyle, rapid industrialisation, increasing road traffic accidents, or competitive sports [1]. The incidence of diaphyseal fractures of the radius, ulna or both is reported to be approximately 1 to 10 per 10,000 persons per year [2]. They are distinct from related injuries in that they donot necessarily disrupt the elbow orwrist joints. However, there is a slight disorientation in radius and ulna decreasing the forearm's rotational amplitude and thereby impairs the positioning andfunction of the hand [2,3]. Open reduction and plate fixation still remains a gold standard for treating skeletally mature patients with simple

Manuscript Received: $24^{\text {th }}$ February 2019

Reviewed: $4^{\text {th }}$ March 2019

Author Corrected: $10^{\text {th }}$ March 2019

Accepted for Publication: $15^{\text {th }}$ March 2019 diaphyseal both-bone forearm fractures [4]. However, many previous studies have documented, many recognized complications following plate fixation. These complications include extensive soft tissue damage, periosteal damage, radioulnar synostosis, injury to neurovascular structures. After the plate removal the incidence of non-union, re-fracture and infective complications were also reported [5].

Considering minimal tissue invasion, as comparedto plating Intramedullary (IM) nailing has been proposed as a better alternative, with considerably lesser incidence of above mentioned complications [6]. Considering these advantages, Intramedullary (IM) nailing is one of widely used methods in clinical practice across the globe. But this method is not without 
risk of complications like is also associated with high rateof non-union, higher risk of injury to neurovascular structures and the need for additional immobilization $[4,7]$.

Although there have been a small number of studies that has reported management of diaphyseal both-bone forearm fractures in children, data on adults is very limited. Also, there is paucity of data in India. Hence, the study aimed to compare the time taken for clinical and radiological union between intramedually nailing versus plating in the management of diaphyseal bothbone forearm fractures among adults. The study also has compared the postoperative functional outcome using Grace \& Eversman functional evaluation score

\section{Materials \& Methods}

Study Design:- The current study was a retrospective comparative study of two different procedures used as a part of routine care in treatment of both bones fractures of forearm. The data was collected by retrospective case record review of the eligible cases operated in our hospital between July 2016 and July 2018, for a 2 year period at a tertiary care teaching hospital located in Kadapa, Andhra Pradesh state, India. Purposive sampling technique was used and all the eligible cases were included in the study.

Inclusion criteria:The study population included adults above 18 years of age of both genders presenting to the department of orthopaedics at a tertiary care teaching hospital.

\section{Exclusion criteria}

- Fracture of forearm bones in children and adolescents.

- Patient not fit for surgery

- Patients with presence of any co-morbidity affecting Activities of daily living (ADL) and bone healing.

- Patients with associated dislocation or intraarticular extensions.

- Compound fracture.

- Cases that were lost to follow up after the procedure, for which the data on the radiological union was unavailable, were excluded from the study.

Considering the retrospective nature of the study, no ethical approval for the study was obtained and obtaining informed written consent was not possible. But informed written consent to provide surgical

\section{Original Research Article}

procedure was obtained for all the patients. Confidentiality of the study subjects was maintained throughout the study.

\section{Operative Procedure}

Plating: In the current studymiddle \& lower third fractures of radius were approached through Dorsal Thompson approach [8] and Volar Henrys approach [9] was used for distal third fracture radius. We have approached Ulna by taking linear and longitudinal incision over the subcutaneous border of the ulna, irrespective of the site. Dynamic Compression Plate (DCP) was used. The plate size and the cortical screw sizes were determined based on pre-operative radiological assessment and

Nailing: In the intramedullary nailing group, radial nail was inserted from the distal end through radial styloid or just lateral to the lister tubercle. The nailing of the ulna was done from the olecranon process at a point 5$8 \mathrm{~mm}$ from the dorsal cortex and $5 \mathrm{~mm}$ from the lateral cortex. This method was adopted to prevent entry into trochlear notch and to compensate for the lateral bow. Square Nails were used in all cases. We have determined the nail length based on the normal limb measurements. The ulnar measurement was done from tip of the olecranon to the ulnar styloid. Considering the difficulty in measuring the radial nail size, it was taken as about 1 inch shorter than the ulna. One $\mathrm{cm}$ is subtracted from the measurement to avoid the risk of driving the nail through the end of bone. We have determined the nail diameter by measurement of medullary canal size using X-ray.

Postoperative Management: In the post-operative period, in allthe subjects, immobilization was done using above elbow slab. Post-operative dressing of surgical wound was performed on day 3 and day 5 for all the subjects. Suture removal was done on 12 th day.

The slab removal was done at the time of suture removal in slab group and at 6 weeks follow up period in IM group. IV antibiotics were given for initial 72 hours followed by oral antibiotics for 5 days. Analgesics and anti-inflammatory drugs and other supplements were given.

The patients were followed regularly at monthly interval for 6 months depending upon the outcome. In each follow up, patients were evaluated radiologically and functionally. The functional outcomes were radiological union and range of motion between the two methods. The fractures were stratified according to 
AO/SIF classification. [10] The patients were assessed using the Grace-Eversmann criteria. [11]

Statistical methods- Descriptive analysis was carried out by mean and standard deviation for quantitative variables, median and inter quartile range for nonnormally distributed quantitative variables, frequency and proportion for categorical variables.

The quantitative outcomes were compared between the two groups by comparing the mean/median values. Independent sample t-test/ Mann-Whitney U test were

\section{Original Research Article}

used to assess statistical significance. Association between quantitative explanatory and outcome variables will be assessed by calculating person correlation coefficient and the data will be represented in a scatter diagram.

The categorical variables were compared between the two groups by cross tabulation and comparison of percentages. Chi square test/Fisher's exact test was used to test statistical significance. $\mathrm{P}$ value $<0.05$ was considered statistically significant. IBM SPSS version 22 was be used for statistical analysis.

\section{Results}

Table-1: Comparison of baseline characteristics of the two study groups.

\begin{tabular}{|c|c|c|c|}
\hline Parameter & Plating $(\mathrm{N}=36)$ & IMN $(\mathrm{N}=\mathbf{2 9})$ & P value \\
\hline Age (mean \pm SD) & $43.2 \pm 4.8$ & $44.78 \pm 5.34$ & 0.214 \\
\hline \multicolumn{4}{|c|}{ Gender } \\
\hline Male & $29(80.55 \%)$ & $24(82.75 \%)$ & \multirow{2}{*}{0.820} \\
\hline Female & $7(19.44 \%)$ & $5(17.24 \%)$ & \\
\hline \multicolumn{4}{|c|}{ Mode of injury } \\
\hline RTA & $24(66.67 \%)$ & $17(58.62 \%)$ & \multirow{4}{*}{0.349} \\
\hline Fall & $9(25 \%)$ & $5(17.24 \%)$ & \\
\hline Sports Injury & $2(5.55 \%)$ & $4(13.79 \%)$ & \\
\hline Others (Occupational injury) & $1(2.77 \%)$ & $3(10.34 \%)$ & \\
\hline BMI & $27.64 \pm 6.7$ & $28.45 \pm 5.30$ & 0.597 \\
\hline \multicolumn{4}{|c|}{ Type of fracture } \\
\hline Closed & $27(75 \%)$ & $19(65.51 \%)$ & \multirow{2}{*}{0.403} \\
\hline Open & $9(25 \%)$ & $10(34.48 \%)$ & \\
\hline \multicolumn{4}{|c|}{ AO/SIF classification } \\
\hline A3 & $17(47.22 \%)$ & $13(44.82 \%)$ & \multirow{2}{*}{0.848} \\
\hline B3 & $19(52.77 \%)$ & $16(55.17 \%)$ & \\
\hline
\end{tabular}

The mean age of subjects in plating group was $43.2 \pm 4.8$ years and $44.78 \pm 5.34$ years it was in IMN group. The difference in the age between the two groups was statistically not significant (P Value 0.214). In plating group, 29 (80.55\%) participants were male and 7 (19.44\%) participants were female. In IMN group, 24 (82.75\%) participants were male and $5(17.24 \%)$ participants were female. The difference in the proportion of gender between study groups was statistically not significant (P value 0.820). In plating group, 24 (66.67\%) participants had RTA, 9 (25\%) participants had fall, 2 (5.55\%) participants had sports Injury and 1 (2.77\%) participant had other injures. In IMN group, 17 (58.62\%) participants had RTA, 5 (17.24\%) participants had fall, 4 (13.79\%) participants had sports Injury and 3 (10.34\%) participants had other injures. The difference in the proportion of mode of injury between study groups was statistically not significant (P value 0.349). The mean BMI of subjects in plating group was $27.64 \pm 6.7$ and $28.45 \pm 5.30$ it was in IMN group.

The difference in the BMI between the two groups was statistically not significant (P Value 0.597). In plating group, 27 (75\%) participants had closed fracture and 9 (25\%) participants had open fracture. In IMN group, 19 (65.51\%) participants were had closed fracture and $10(34.48 \%)$ participants had open fracture. The difference in the proportion of type of fracture between study groups was statistically not significant ( $\mathrm{P}$ value 0.403$)$. In plating group, 17 (47.22\%) participants were A3 classification and 19 (52.77\%) participants were B3 classification. In IMN group, 13 (44.82\%) were A3 classification and $16(55.17 \%)$ participants were B3 classification. The difference in the proportion of AO/SIF classification between study groups was statistically not significant ( $\mathrm{P}$ value 0.848 ). (Table 1 ) 
Original Research Article

Table-2: Comparison of baseline characteristics of the two study groups.

\begin{tabular}{|c|c|c|c|}
\hline Parameter & Plating (N=36) & IMN (N=29) & P value \\
\hline Operating time in minutes & $68 \pm 6.37$ & $54 \pm 5.57$ & 0.001 \\
\hline Time taken for radiological union (weeks) & $11.23 \pm 2.16$ & $13.87 \pm 3.32$ & 0.003 \\
\hline \multicolumn{3}{|c|}{ Range of motion } & $78 \pm 16.28$ \\
\hline Supination & $86 \pm 15.37$ & $74 \pm 15.33$ & 0.046 \\
\hline Pronation & $78 \pm 14.85$ & 0.291 \\
\hline
\end{tabular}

The mean operating time in minutes of subjects in plating group was $68 \pm 6.37$ and $54 \pm 5.57$ it was in IMN group. The difference in the operating time in minutes between the two groups was statistically significant ( $\mathrm{P}$ Value 0.001$)$. The mean time taken for radiological union of subjects in plating group was $11.23 \pm 2.16$ weeks and $13.87 \pm 3.32$ weeks it was in IMN group. The difference in the time taken for radiological union between the two groups was statistically significant (P Value 0.003). The mean supination of subjects in plating group was $86 \pm 15.37$ and $78 \pm 16.28$ it was in IMN group. The difference in the supination between the two groups was statistically significant (P Value 0.046). The mean pronation of subjects in plating group was $78 \pm 14.85$ and $74 \pm 15.33$ it was in IMN group. The difference in the pronation between the two groups was statistically not significant (P Value 0.291). (Table 2)

Table-3: Comparison of functional outcome as assessed by Grace \&Eversman functional evaluation score.

\begin{tabular}{|c|c|c|c|}
\hline Functional outcome & Plating (N=36) & IMN (N=29) & P value \\
\hline Excellent & $27(75 \%)$ & $23(82.75 \%)$ & \\
\cline { 1 - 3 } Good & $6(16.66 \%)$ & $4(13.79 \%)$ & $*$ \\
\cline { 1 - 3 } Acceptable & $3(8.33 \%)$ & $1(3.44 \%)$ & \\
\hline Unacceptable & $0(0 \%)$ & $1(3.44 \%)$ & \\
\hline
\end{tabular}

* No statistical test was applied-due to 0 subjects in the cell

In plating group, $27(75 \%)$ participants had excellent functional outcome, 6 (16.66\%) participants had good functional outcome and $3(8.33 \%)$ participants had acceptable functional outcome. In IMN group, $23(82.75 \%)$ participants had excellent functional outcome, 4 (13.79\%) participants had good functional outcome, 1 (3.44\%) participant had acceptable functional outcome and 1 (3.44\%) participant had unacceptable functional outcome. (Table 3)

\section{Discussion}

In the current study, the mean age of subjects in plating group was $43.2 \pm 4.8$ years and $44.78 \pm 5.34$ years it was in IMN group. In plating group, $29(80.55 \%)$ participants were male and $7(19.44 \%)$ participants were female. In IMN group, $24(82.75 \%)$ participants were male and $5(17.24 \%)$ participants were female. In plating group, 24 (66.67\%) participants had RTA, 9 (25\%) participants had fall, $2(5.55 \%)$ participants had sports Injury and $1(2.77 \%)$ participant had other injures.

In IMN group, $17(58.62 \%)$ participants had RTA, 5 (17.24\%) participants had fall, 4 (13.79\%) participants had sports Injury and $3(10.34 \%)$ participants had other injures. The mean BMI of subjects in plating group was $27.64 \pm 6.7$ and $28.45 \pm 5.30$ it was in IMN group. In plating group, 27 (75\%) participants had closed fracture and $9(25 \%)$ participants had open fracture. In IMN group, $19(65.51 \%)$ participants were had closed fracture and $10(34.48 \%)$ participants had open fracture. In plating group, $17(47.22 \%)$ participants were A3 classification and $19(52.77 \%)$ participants were B3 classification. In IMN group, $13(44.82 \%)$ were A3 classification and $16(55.17 \%)$ participants were B3 classification. In the study by Zhang, X. F., et al [4], there were 21 cases of plate fixation (12 males, 9 females) and 22 cases IM nailing group (12 males, 10 females). The mean age of the participants was $38.22 \pm$ 1.15 in plating and $37.80 \pm 0.80$ for IMN group. In plate fixation group 8 participants had Type A fracture, 5 had type $\mathrm{B}$ fracture and 8 had type $\mathrm{C}$ fracture.

In IMN group 7 participants had Type A fracture, 7 had type $\mathrm{B}$ fracture and 8 had type $\mathrm{C}$ fracture. 
In the present study, the mean operating time in minutes of subjects in plating group was $68 \pm 6.37$ and $54 \pm 5.57$ it was in IMN group. The mean time taken for radiological union of subjects in plating group was $11.23 \pm 2.16$ weeks and $13.87 \pm 3.32$ weeks it was in IMN group. The mean supination of subjects in plating group was $86 \pm 15.37$ and $78 \pm 16.28$ it was in IMN group. The mean pronation of subjects in plating group was $78 \pm 14.85$ and $74 \pm 15.33$ it was in IMN group. In the study by Zhang, X. F., et al[4]plating group the mean operating time was $2.17 \pm 0.25$ in plating group and $1.17 \pm 0.27$ in IMN group.The time to union of IMN group (4.2 months) was significantly shorter than that of plating group (5.3 months).

In the present study, in plating group, 27(75\%) participants had excellent functional outcome, $6(16.66 \%)$ participants had good functional outcome and $3(8.33 \%)$ participants had acceptable functional outcome. In IMN group, $23(82.75 \%)$ participants had excellent functional outcome, $4(13.79 \%)$ participants had good functional outcome, 1 (3.44\%) participant had acceptable functional outcome and $1(3.44 \%)$ participant had unacceptable functional outcome.

In the study by Zhang, X. F., et al [4] in plating group, excellent outcome was seen in 11 participants, good outcome was seen in 3 participants, fair outcome was seen in 5 participants and poor outcome was seen in 2 participants. In IMN group, excellent outcome was seen in 11 participants, good outcome was seen in 5 participants, fair outcome was seen in 5 participants and poor outcome was seen in 1 participant.

In the current study the difference between the functional outcome groups could not be determined statistically. This study had major disadvantage with regard to its retrospective nature. The confounders were not considered in the study and the small sample size and non-probability sampling of the study population reduced the generalizability of the study.

\section{Conclusion}

The findings of the present study suggest that, the plating group has better results in terms of radiological union and range of motion. However the surgical time was less in IMN group. There was no difference between the functional outcomes between the groups.

To determine whether intramedullary fixation is a viable alternative to plate and screw fixation, we need a prospective, randomized trial comparing plate and IMN for diaphyseal fractures of both forearm bones.

\section{Original Research Article}

Contributions by First author: wrote the manuscript followed by data collection and conducting a research. Verification of the results and manuscript was also done by the first author.Second author: conducting the research and wrote the manuscript

All authors discussed the results and contributed to the final manuscript.

What this study adds to existing knowledge: This study adds to research on adult diaphyseal both-bone forearm fractures adults in India which is very limited. It was also seen that plating in the management of diaphyseal both-bone forearm fractures among adults was better compared to Intramedually nailing.

Conflict of interest: None declared.

Funding: Nil, Permission from IRB: Yes

\section{References}

1. Al-Sadek TA, Niklev D, Al-Sadek A. Diaphyseal Fractures of the Forearm in Adults, Plating Or Intramedullary Nailing Is a Better Option for the Treatment? Open Access Maced J Med Sci. 2016;4 (4) : 670-3.

2. Ambhore N, S B. A comparative study between plating \& intramedullary nailing for displaced diaphyseal fractures of radius and ulna in adults. Int $\mathbf{J}$ surg Orthopedics. 2018;4(1):29-36.

3. Schulte LM, Meals CG, Neviaser RJ. Management of adult diaphyseal both-bone forearm fractures. J Am Acad Orthop Surg. 2014Jul;22(7):437-46. doi: 10.5435/ JAAOS-22-07-437.

4. Zhang XF, Huang JW, Mao HX, et al. Adult diaphyseal both-bone forearm fractures: A clinical and biomechanical comparison of four different fixations. Orthop Traumatol Surg Res. 2016 May;102(3):319-25. doi: 10.1016/j.otsr.2015.11.019. Epub 2016 Mar 5.

5. Henle P, Ortlieb K, Kuminack K, et al. Problems of bridging plate fixation for the treatment of forearm shaft fractures with the locking compression plate. Arch Orthop Trauma Surg. 2011 Jan;131(1):85-91. doi: 10. 1007/s00402-010-1119-y. Epub 2010 Jun 3.

6. Lee YH, Lee SK, Chung MS, et al. Interlocking contoured intramedullary nail fixation for selected diaphyseal fractures of the forearm in adults. $\mathrm{J}$ Bone Joint Surg Am. 2008 Sep; 90(9):1891-8. doi: 10.2106/ JBJS. G.01636. 


\section{Original Research Article}

7. Visna P, Vlcek M, Valcha M, et al. [Management of diaphyseal forearm fractures using LCP angle- stable fixation devices and intramedullary nailing]. Rozhl Chir. 2009 Dec; 88 (12):708-15.

8. Thompson JE. Anatomical methods of approach in operations on the long bones of the extremities. Ann Surg. 1918 Sep;68(3):309-29.

9. Henry MH, Griggs SM, Levaro F, et al. Volar approach to dorsal displaced fractures of the distal radius. Tech Hand Up Extrem Surg. 2001 Mar; 5 (1): 31-41.

10. Müller ME NS, Koch P, Schatzker, J. Classification AO des fractures. 1987. Tome I. Les os longs. Berlin: Springer-Verlag. 1987.

11. Grace TG, Eversmann WW Jr. Forearm fractures: treatment by rigid fixation with early motion. J Bone Joint Surg Am. 1980 Apr;62(3):433-8.

\section{How to cite this article?}

Reddy R.C, M. Anil Kumar. A retrospective comparative study of intramedually nailing versus plating in the management of diaphyseal both-bone forearm fractures among adults. Surgical Update: Int J surg Orthopedics. 2019;5 (2):94-99.doi:10.17511/ijoso.2019.i02.05. 